\title{
Editorial \\ Metabolic Syndrome among South Asians
}

Journal of the Ceylon College of Physicians, 2018, 49, 45-47

South Asian countries include India, Pakistan, Bangladesh, Sri Lanka and Maldives and has over onefifth of the world's population, making it most densely populated region in the world. ${ }^{1}$ Metabolic syndrome is a cluster of disease conditions caused by insulin resistance leading to diabetes mellitus and cardiovascular diseases. South Asians have an increased risk of developing this syndrome. ${ }^{2,3}$

The prevalence of metabolic syndrome among South Asians varies according to region, extent of urbanization, lifestyle patterns, socioeconomic and cultural factors. ${ }^{4}$ About one-third of the urban population in large cities in India have metabolic syndrome. ${ }^{5,6}$ One community-based study from eastern India has measured the prevalence of metabolic syndrome as $31.4 \%$, with females having a much higher prevalence $(48.2 \%)$ than males $(16.3 \%))^{7}$ In another study from South India, 31\% had abdominal obesity, $46 \%$ had hypertriglyceridemia, $66 \%$ had low high-density lipoprotein (HDL) cholesterol, 55\% had hypertension, and $27 \%$ had raised fasting plasma glucose levels. ${ }^{8}$ The prevalence of metabolic syndrome in rural community is reasonably low compared to the urban community. ${ }^{9}$

The prevalence of childhood metabolic syndrome is also on the rise. A survey in North India found the prevalence of metabolic syndrome in adolescents to be $4.2 \% .{ }^{10}$ The metabolic syndrome during childhood is known to be a precursor of adult metabolic syndrome.

The central obesity common among South Asians and is associated with leptin and adiponectin levels in the body. The central obesity is significantly associated with low HDL cholesterol, increased triglycerides and insulin resistance. ${ }^{11}$ Lower cut-offs for diagnosis of overweight and obesity, i.e. $23 \mathrm{~kg} / \mathrm{m}^{2}$ and $25 \mathrm{~kg} / \mathrm{m}_{2}$ or greater, respectively are recommended by the World Health Organization for South Asian populations. ${ }^{12}$ The recommended waist circumference cut-offs for South Asians are $\leq 90 \mathrm{~cm}$ for males and $\leq 80 \mathrm{~cm}$ for females. ${ }^{13}$

The prevalence of insulin resistance and diabetes mellitus are higher among South Asians compared to other ethnic groups. ${ }^{14}$ As diabetes mellitus is the major risk factor of cardiovascular diseases, the fasting glucose cut-off has been lowered to $100 \mathrm{mg} / \mathrm{dL}^{15}$

Dyslipidemia is common among South Asians who typically have lower HDL cholesterol and higher levels of low-density lipoprotein (LDL) cholesterol compared to Caucasians. ${ }^{16}$ Hypertriglyceridaemia is also commoner among South Asians. ${ }^{17}$

A higher percentage of hypertensive patients have insulin resistance compared to non-hypertensive patients. ${ }^{18}$ Hypertensive patients with South Asian origin have higher mortality from cardiovascular diseases compared to patients of African origin although hypertension is more prevalent among the latter. ${ }^{19}$

A number of studies have shown that skinfold thickness is thicker in South Asians compared to Caucasians across all age groups. ${ }^{20}$ Truncal subcutaneous fat is an important determinant abdominal obesity for insulin sensitivity among South Asians. ${ }^{21}$

The prevalence of non-alcoholic steatohepatitis is higher among South Asians and is an important associate of insulin resistance and metabolic syndrome..$^{22}$ Both obese and non-obese Indians with non-alcoholic steatohepatitis have significantly higher insulin resistance compared to those without nonalcoholic steatohepatitis. ${ }^{22}$ Polycystic ovarian syndrome among South Asians is associated with younger age of presentation, more severe symptoms and greater degree of insulin resistance and is more prevalent compared to Caucasians. ${ }^{23}$

South Asian adults and children develop hyperglycemia, hypertension, and hypertriglyceridemia occur at lower levels of body mass index and waist circumference. ${ }^{24}$ The interesting $Y$ - $Y$ hypothesis in which, the researchers Yajnik from India and Yudkin from United Kingdom demonstrated that at a similar body mass index of $22.3 \mathrm{~kg} / \mathrm{m}^{2}$, body fat percentage among Indians was $21.2 \%$ while this was $9.1 \%$ among Caucasians. ${ }^{25}$

South Asians consume higher amounts of carbohydrates compared to Europeans and this may 
lead to hyperinsulinemia, postprandial hyperglycemia, high serum triglycerides and low HDL cholesterol levels associated with insulin resistance. ${ }^{26}$

The prevention of metabolic syndrome includes behavior modifications, dietary modifications, regular exercises, cessation of smoking and reduce alcohol intake. Although an individual-based approach may be beneficial, population-based community intervention programs are more important to prevent metabolic syndrome successfully.

It is essential to identify and correct behavioral problems related to eating habits especially in children and younger adults. ${ }^{27}$ Lifelong continuation of these corrective measures are essential. It is difficult to change habits in older individuals.

Nutrition during the perinatal period and early childhood may influence insulin resistance and metabolic syndrome in later life. Therefore, both maternal malnutrition and childhood overnutrition should be avoided.

Dietary modifications, including a reduction of saturated fat, refined carbohydrates and sweetened beverages, help reducing obesity during childhood. Salt restriction is important to prevent hypertension. Dietary fiber containing foods including green leaves, vegetables and fruits need to be encouraged to prevent obesity.

Daily exercises should be promoted for reduction of weight and to increase insulin sensitivity. Exercises reduce blood pressure, increase HDL-cholesterol and reduce triglyceride levels. ${ }^{28}$

Lifestyle modifications to prevent obesity and metabolic syndrome should be encouraged at school level as it is easy to change unhealthy lifestyle behaviors at this age. ${ }^{29}$ At risk people should be identified during childhood and strategies should be implemented to prevent metabolic syndrome and its components. ${ }^{30}$

High-risk individuals and vulnerable populations should be evaluated regularly to diagnose metabolic syndrome or its components at the earliest possible stage using minimum available resources. Aggressive lifestyle modification is the most important aspect of the prevention and management of metabolic syndrome and medications should be stated when such individuals reach thresholds for drug therapy. ${ }^{31}$

\section{References}

1. http://millenniumindicators.un.org/unsd/methods/m49/ m49regin.htm\#asia

2. McKeigue PM, Shah B, Marmot MG. Relation of central obesity and insulin resistance with high diabetes prevalence and cardiovascular risk in South Asians. Lancet. 1991; 337: 382-6.

3. McKeigue PM. Metabolic consequences of obesity and body fat pattern: Lessons from migrant studies. Ciba Found Symp. 1996; 201: 54-64.

4. Misra A, Khurana L. The metabolic syndrome in South Asians: Epidemiology, determinants, and prevention. Metab Syndr Relat Disord. 2009; 7: 497-514.

5. Misra A, Khurana L. Obesity and the Metabolic Syndrome in developing countries. J Clin Endocrinol Metab. 2008; 93: S9-30.

6. Das M, Pal S, Ghosh A. Prevalence of cardiovascular disease risk factors by habitat: A study on adult Asian Indians in West Bengal, India. Anthropol Anz. 2011; 68: 253-64.

7. Das M, Pal S, Ghosh A. Association of metabolic syndrome with obesity measures, metabolic profiles, and intake of dietary fatty acids in people of Asian Indian origin. $J$ Cardiovasc Dis Res. 2010; 1: 130-5.

8. Kanjilal S, Shanker J, Rao VS, Khadrinarasimhaih NB, Mukherjee M, lyengar SS, et al. Prevalence and component analysis of metabolic syndrome: An Indian atherosclerosis research study perspective. Vasc Health Risk Manag. 2008; 4: 189-97.

9. Kamble P, Deshmukh PR, Garg N. Metabolic syndrome in adult population of rural Wardha, central India. Indian J Med Res. 2010; $132: 701-5$.

10. Singh R, Bhansali A, Sialy R, Aggarwal A. Prevalence of metabolic syndrome in adolescents from a north Indian population. Diabet Med. 2007; 24: 195-9.

11. Shah A, Hernandez A, Mathur D, Budoff MJ, Kanaya AM. Adipokines and body fat composition in South Asians: Results of the Metabolic Syndrome and Atherosclerosis in South Asians Living in America (MASALA) study. Int $J$ Obes (Lond) 2011.

12. The Asia-Pacific Perspective: Redefining Obesity and Its Treatment. Melbourne: Health Communications Australia; 2000. WHO/IASO/IOTF.

13. WHO Expert Consultation 2004. Appropriate body-mass index for Asian populations and its implications for policy and intervention strategies. Lancet 2004; 363: 157-63.

14. Venkataraman R, Nanda NC, Baweja G, Parikh N, Bhatia V. Prevalence of diabetes mellitus and related conditions in Asian Indians living in the United Status. Am J Cardiol. 2004; 94: 977-80.

15. Eapen D, Kalra GL, Merchant N, AroraA, Khan BV. Metabolic syndrome and cardiovascular disease in South Asians. Vasc Health Risk Manag. 2009; 5: 731-43. 
16. Elena Flowers, César Molina, Ashish Mathur, Gerald M. Reaven. Use of plasma triglyceride/high-density lipoprotein cholesterol ratio to identify increased cardio-metabolic risk in young, healthy South Asians. Indian J Med Res. 2015; 141(1): 68-74.

17. Ozlem Bilen, Ayeesha Kamal, Salim S Virani. Lipoprotein abnormalities in South Asians and its association with cardiovascular disease: Current state and future directions. World J Cardiol. 2016; 8(3): 247-57.

18. Garcia-Puig J, Ruilope LM, Luque M, Fernandez J, Ortega R, Dal-Re R. Glucose metabolism in patients with essential hypertension. Am J Med. 2006; 119: 318-26.

19. Cappuccio FP. Ethnicity and cardiovascular risk: Variations in people of African ancestry and South Asian origin. J Hum Hypertens. 1997; 11: 571-6.

20. Misra A. Impact of ethnicity on body fat patterning in Asian Indians and Blacks: Relationship with insulin resistance. Nutrition 2003; 19: 815-6.

21. Kamath SK, Hussain EA, Amin D, Mortillaro E, West B, Peterson CT, et al. Cardiovascular disease risk factors in 2 distinct ethnic groups: Indian and Pakistani compared with American premenopausal women. Am J Clin Nutr. 1999; 69: 621-31.

22. Misra A, Misra R, Wijesuriya M, Banerjee D. The metabolic syndrome in South Asians: Continuing escalation and possible solutions. Indian J Med Res. 2007; 125: 345-54.

23. Wijeyaratne $\mathrm{CN}$, Balen $\mathrm{AH}$, Barth JH, Belchetz PE. Clinical manifestations and insulin resistance (IR) in polycystic ovary syndrome (PCOS) among South Asians and Caucasians: Is there a difference? Clin Endocrinol (Oxf) 2002; 57: 343-50.
24. Vikram NK, Pandey RM, MisraA, Sharma R, Devi JR, Khanna $\mathrm{N}$. Non-obese (body mass index $<25 \mathrm{~kg} / \mathrm{m} 2$ ) Asian Indians with normal waist circumference have high cardiovascular risk. Nutrition 2003; 19: 503-9.

25. WHO Expert Consultation 2004. Appropriate body-mass index for Asian populations and its implications for policy and intervention strategies. Lancet 2004; 363: 157-63.

26. Burden ML, SamantaA, Spalding D, Burden AC. A comparison of the glycaemic and insulinaemic effects of an Asian and a European meal. Pract Diabetes Int. 1994; 11: 208-11.

27. MisraA, Khurana L, Vikram NK, Goel A, Wasir JS. Metabolic syndrome in children: Current issues and South Asian perspective. Nutrition 2007; 23: 895-910.

28. Tharmegan Tharmaratnam, Mina A. Iskandar, Sally Doherty, Katrina A. D'Urzo, Swana Kopalakrishnan, Tyler Cameron Tabobondung, Prasaanthan Gopee-Ramanan, Seyon Sivagurunathan, Nirunthan Sivananthan. The Role of Physical Activity Prescription in Cardiovascular Disease Prevention Amongst South Asian Canadians. Front Cardiovasc Med. 2018; 5: 165. Published online 2018 Nov 14.

29. Bhatia V. IAP National Task Force for Childhood Prevention of Adult Diseases: Insulin resistance and type 2 diabetes mellitus in childhood. Indian Pediatr. 2004; 41: 443-57.

30. Singhal N, MisraA, Shah P, Gulati S, Bhatt S, Sharma S, et al. Impact of intensive school-based nutrition education and lifestyle interventions on insulin resistance, $\beta$-cell function, disposition index, and subclinical inflammation among Asian Indian adolescents: A controlled intervention study. Metab Syndr Relat Disord. 2011; 9: 143-50.

31. Prabhakaran D, Reddy KS. The metabolic syndrome: Looking beyond the debates. Clin Pharmacol Ther. 2011; 90: 19-21.

\section{Namal Wijesinghe \\ Co Editor \\ JCCP}

